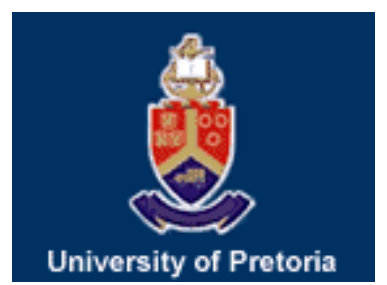

University of Pretoria

Department of Economics Working Paper Series

\author{
An Analysis of the Inward Cross-border Mergers and Acquisitions in the UK: \\ A Macroeconomic Perspective \\ Agyenim Boateng \\ Nottingham University Business School, University of Nottingham, Ningbo Campus, PR China \\ Ruthira Naraidoo \\ University of Pretoria \\ Moshfique M. Uddin \\ School of Accounting \& Financial Services, Leeds Metropolitan University, UK \\ Working Paper: 2009-24 \\ November 2009
}

Department of Economics

University of Pretoria

0002, Pretoria

South Africa

Tel: +27 124202413

Fax: +27 123625207 


\title{
An Analysis of the Inward Cross-border Mergers and Acquisitions in the UK: A Macroeconomic Perspective
}

\author{
Agyenim Boateng ${ }^{\mathrm{a} *}$, Ruthira Naraidoo ${ }^{\mathrm{b}}$ and Moshfique M. Uddin ${ }^{\mathrm{c}}$ \\ ${ }^{a}$ Associate Professor of Finance, Nottingham University Business School, University of \\ Nottingham, Ningbo Campus, PR China \\ ${ }^{\mathrm{b}}$ Senior Lecturer in Economics, Faculty of Economics \& Management Science, University of \\ Pretoria, South Africa \\ ${ }^{c}$ Lecturer in Finance, School of Accounting \& Financial Services, Leeds Metropolitan University, \\ UK
}

\begin{abstract}
Most of the growth in international production over the past decade has been carried out via cross-border mergers and acquisitions. Yet previous empirical work relating to CBM\&As has been confined to firm-specific factors. This is against the backdrop that researchers have not been able to develop a coherent theory explaining the increasing trends of CBM\&As activity. Building on prior studies, this study attempts to extend the few existing studies by using a simple empirical nonlinear framework to analyse the number of cross-border mergers and acquisitions inflows between 1987 and 2008 into the UK from a macroeconomic perspective. The main findings are that the response of the inflow is asymmetric as there is more persistence during stock market booms versus recessions. There are asymmetries with respect to relative prices suggesting that an improvement in the terms of trade leads to higher inflows once the growth of stock prices is above a threshold level of $8 \%$. Other factors which have significant bearing on CBM\&As inflows are the rate of inflation and growth in real GDP.
\end{abstract}

Keywords: Cross-border mergers \& acquisitions, Macro-economic factors, UK, nonlinear LSTAR

*Nottingham University Business School, China Campus, 199 Taikang East Road, Ningbo Zhejiang Province. 315100, PR China. Tel: + 44 (0) 555 4455, Fax +44 (0) 4444, E-mail: agyenim.boateng@nottingham.edu.cn. Also author for correspondence. 


\section{An Analysis of the Inward Cross-border Mergers and Acquisitions in the UK: A Macroeconomic Perspective}

\section{Introduction}

The incidence of cross-border mergers \& acquisitions (CBM\&As) has accelerated over the past two decades (UNCTAD, 2000, 2006). Commensurate with the rising trends of mergers and acquisitions are a number of studies investigating the merger phenomenon. However, it is important to point out that merger studies in finance have concentrated in two areas: (i) studies that examine the theories and motivation for M\&As (see Steiner, 1975; Sharma and Ho, 2002 and Hodgkinson and Partington, 2007); and ii) studies that investigate the wealth gains of the acquirer and target firms using event study methodology (Conn and Connel, 1990; Mathur, Ragan, Chhachhi and Sundaram 1994; Markides and Ittner, 1994; Aw and Chatterjee, 1994; Gregory and McCorriston, 2005). Prior literature indicates that relatively few studies have been carried out on the relationship between macro-economic factors and mergers $\&$ acquisitions. The few studies in the area have approached the topic from two methodological standpoints. One stream of studies has used linear time series models to examine macro-economic influences on M\&As (see Shugart and Tollison, 1984; McCann, 2001; Yagil, 1996). The second group of studies have analysed macro-economic determinants by using non-linear time series models to capture wave behaviours in M\&A (see Town, 1992; Resende, 1999; Carow, Heron and Saxton, 2004). More specifically, researchers in the latter group have used Markov Switching Models to permit the notion of abrupt shifts and show the degree of persistence of unobserved states for M\&As. A more promising line of research is to extend the non-linear time series models that naturally accommodate the notion of shifts associated with waves and patterns of mergers and acquisitions behaviour. This study departs from previous studies and uses a Smooth Transition Auto-Regressive (STAR) process to 
model a regime shift in the adjustment of UK CBM\&A inflows to macroeconomic factors. This approach is significant in that economic intuition suggests that the impact of macroeconomic determinants relating to inward CBM\&As would differ depending on whether the economy is in a stock market boom or recession and therefore displaying asymmetric adjustments in the response to investment inflows. To the best of our knowledge, this is the first attempt to model and compare across regimes the UK cross border mergers and acquisitions inflows using a nonlinear function which is 'smooth' by nature exploring the view that the wave behaviors may not be abrupt as indicated by Markov Switching specifications.

Building on prior studies, this paper considers a number of important questions in respect of inward CBM\&As into the UK for the period of 1987 to 2008. First, do macro economic fundamentals explain the inward CBM\&As? Second, is the response symmetric? In other words, do CBM\&As inflows have different adjustments depending on whether the return to such investment is above or below some threshold level?

We attempt to answer the above research questions by using a simple nonlinear framework to analyse the macro economic influences on CBM\&As inflows into the UK over 1987 - 2008 period. Our main findings suggest that growth in the FTSE, growth in real GDP, growth in the real exchange rate and inflation explain about 65 percent of the variation in CBM\&As inflows into the UK. Our results also indicate that the response of the inflow is asymmetric and there appears to be a strong persistence during stock market booms versus recessions. Moreover, CBM\&As inflows respond asymmetrically and positively to an improvement in the terms of trade once the growth of stock prices is above a threshold level of $8 \%$. However, growth in real GDP and the rate of inflation exert statistically negative influences on CBM\&As inflows. 
The rest of the paper is organized along the following lines. The next section reviews the theoretical regarding the relationships between macro-economic determinants and cross-border mergers and acquisitions activity. Section 3 presents the nonlinear modelling framework that accounts for the macro-economic influences on CBM\&As. Section 4 estimates the model and discusses the findings of the study. The last section provides a summary of the conclusion and discusses the implications of the study.

\section{Theoretical Background}

Prior studies highlight a wide array of factors believed to give rise to CBM\&As activities ranging from mainstream industrial organization theory to economic factors in the home country. We discuss these factors at aggregate level below:

\section{Exchange Rate}

Industrial organization view suggests that, it makes no difference how acquisitions are financed because acquirers in the international market for corporate control have the same access to international capital markets (Hymers, 1960; Kindleberger, 1969; Vernon, 1966). There is, therefore, no real role for the exchange rate under the industrial organisation theory. For example, it is argued that when the pound sterling depreciates, the United Kingdom becomes a cheaper place for any firm to produce. However, the depreciation does not change foreign acquirers' opportunities relative to those of local British investors. The irrelevancy of exchange rate in respect to foreign acquisitions is intuitively appealing but inconsistent with what happens in the real world (Froot and Stein, 1991). In their study of the relationship between exchange rate and FDI, Froot and Stein (1991) found that 10 percent dollar depreciation is associated with 
additional FDI inflows of about $\$ 5$ billion. According to Froot and Stein (1991), foreign firms are wealthier relative to domestic ones when dollar is depreciating and we should observe a negative relationship between inward acquisitions and exchange rate and the converse is true if dollar is appreciating. This line of thinking is supported by Vasconcellos, Madura and Kish (1990) who suggested that firms from countries with strong currencies in relation to their counterparts from foreign countries should see an upward trend in outward acquisitions. This is because a depreciated currency can give foreigners an edge in buying control of corporate assets in that a strong currency makes foreign assets cheaper to acquire. Studies by Harris and Ravenscraft (1991), Kang (1993), Dewenter (1995) and Goergen and Renneboog (2004) have also rendered some support for this notion and pointed out that firms from countries with appreciating currency should act as an acquirer whereas firms from countries with depreciating currency should be a target on the grounds that strong currency would reduce the acquisition price and transaction costs.

On the other hand, the model by Cushman (1984) suggests that the relationship between exchange rate and CBM\&As could be indeterminate. Using a two - period world in which the firm maximizes the certainty equivalent of future real profits expressed in domestic currency, a four case scenario was examined in which the firm: i) produce and sell abroad with foreign input; ii) produce and sell abroad with imported inputs from home; iii) produce and sell at home with foreign inputs; iv) produce at home and abroad for foreign sale. Cushman (1984) concluded that the impact of a change in exchange rate levels or expectations on the levels of foreign direct investment (FDI) depends on the investor's revenue and cost configuration. Thus the effect of a rise in the expected change in real exchange rate is higher for FDI in cases 1-3 but ambiguous in case 4. More recently, Kish and Vasconcellos (1993) suggest that the relationship may not be 
straightforward in that as a country's currency strengthens, the future profits to be repatriated from the acquiring firm's subsidiary will have a lower discounted value. In this study, we contend that an increase in relative prices would lead to a decrease in the UK's competitiveness and consequently a fall in merger inflows due to huge capital needed for such investments.

\section{Other Economic Factors}

Economic reasons, certainly, have been the primary motivation for business acquisitions (Yantell

and Gartrell, 1988). While scholars have examined and produced a myriad of reasons for mergers and acquisitions at aggregate level, there remains empirical controversy and no consensus has emerged from prior studies.

\section{Stock prices and Inflation}

One of the first attempts to find out which economic factors contribute to merger activity by Weston (1953) indicated that stock prices and inflation exert considerable influence. In an examination of changes in quarterly merger activities in the US market during 1895 to 1920 , Nelson (1959) found a positive correlation between changes in the merger activities and changes in the stock prices and inflation. Geroski, 1984; and Evenett, 2003 have also rendered support for both share price and inflation. Melicher, Ledolter and D'Antonio (1983) and Benzing (1991) also argue that higher stock prices indicate the prospects of future economic growth and consequently higher level of M\&As activities. On the other hand, Vasconcellos and Kish (1998) found that a depressed US stock market relative to foreign stock market encourages foreign acquisitions of US companies. McCann (2001) found that the lower the UK stock market index, the more the UK inward CBM\&As but the relationship was not statistically significant. However, Golbe and White (1988) found a negative relationship between stock price and M\&As. 


\section{Gross Domestic Product and Interest rates}

Other studies suggest that gross domestic product (Becketti, 1986; Ali-Yrkko, 2002), interest rates (Becketti, 1986; Diebold and Lindner, 1996) influence mergers and acquisitions. For example, Ali-Yrkko (2002) argues that the bigger economy as reflected by the size of GDP should spur companies to engage in more acquisition activities. This is because higher size of absolute GDP or higher level of GDP growth signifies greater demand in the economy which may lead the economy to reallocate its resources in order to ensure their optimum use. This urge for reallocation of resources motivates the M\&As formation in the economy. The positive impact of GDP on the aggregate flow of M\&As has been supported by Resende (2005), Nakamura (2004) and Crook (1995) who concluded that there exists a positive relation between GDP and aggregate domestic M\&As activities. In the context of CBM\&As, similar conclusion has been drawn by a number of scholars. Anand and Kogut (1997) and Globerman and Shapiro (1999) suggest that higher GDP in the host country would lead to more inward M\&As, because of the possibility of higher demand and potential high profitability within the host economy.

On the other hand, Healy and Palepu (1993) contend that higher GDP may result in higher level of cash reserve in the hands of local firms and these firms may end up spending the excess funds to acquire local firms to increase the size of their companies and gain market power. Moreover, it may be argued the availability of cash reserves in the hands of local firms may lead to higher competition between local acquirers and foreign acquirers thereby resulting in excess valuation of the target. Given the existence of market imperfections in the global market for product and service such as transaction costs, costs associated with barriers to entry and liability of "foreignness", acquisitions may tilt in favour of domestic acquiring firms when it comes to competition between local and foreign acquirers. It may be argued that the relationship between 
GDP and inward CBM\&As may be negative in that it may be cheaper for domestic firms to invest domestically rather than go abroad and incur transaction costs due to risk and liability of "foreignness" associated with foreign investments.

Regarding the interest rates and M\&A activities, scholars argue that the relationship between M\&As and interest rate lies with the fact that lower interest rate reduces the cost of financing and encourages more M\&As formation (Melicher, Ledolter and D'Antonio, 1983). The inverse relation between interest rate and M\&As formation has also been supported by Yagil (1996) and Haque, Harnhirun and Shapiro (1995). On the relationship between inward CBM\&As and interest rate, Kish and Vasconcellos (1993) suggest that higher interest rate in the host country discourage inflow of CBM\&As.

\section{Data}

Cross border merger \& acquisition inflow $(C B M A I N)$ is measured by the number of mergers and acquisitions made in the UK by foreign companies, GFTSEALL is the annual growth rate in the UK all share price index, GRGDP is the annual growth rate in real gross domestic product at constant 2001 market price, $R O I$ is the percentage real interest rate on three-month UK treasury bills, GRXR is the annual growth rate in the real effective exchange rate index and $I N F$ is the annual proportional change in the consumer price index.

\section{Empirical Model}

A number of researchers have suggested that a nonlinear specification tends to reveal structure in data that might be missed by classical linear methods. To this end, we employ a framework which has similarities with Smooth Transition Auto-Regressive (STAR) models (Granger and Terasvirta 1993; van Dijk et al. 2002), in that the endogenous variable is determined by a 
weighted average of regimes with endogenous regime weights. We consider a nonlinear function of the form:

$\operatorname{CBMAIN}_{t}=\lambda_{t}\left(q_{t-d} ; \gamma, g\right) R_{L t}+\left(1-\lambda_{t}\left(q_{t-d} ; \gamma, g\right)\right) R_{U t}+\varepsilon_{t}$

where

$R_{j t}=\alpha_{j 0}+\alpha_{j i}(L)$ CBMAIN $_{t}+\alpha_{j f}$ GFTSEALL $_{t}+\alpha_{j y} G R G D P_{t}+\alpha_{j r} R O I_{t}+\alpha_{j e} G R X R_{t}+\alpha_{j \pi} I N F_{t}$

for $j=L, U$ and $\lambda_{t}\left(q_{t-d} ; \gamma, g\right)$ is a nonlinear function. $\alpha_{0 j}$ are constants for the lower and upper

regime respectively, $\alpha_{j i}(L)=\alpha_{j i_{1}} L+\ldots . \alpha_{j i_{n}} L^{n}$ is the lag polynomial in $C B M A I N_{t}$ cross-border

mergers and acquisitions inflow, $\alpha_{j i}(L)$ denoting a measure of CBMAIN persistence.

In this study, we consider the issue of whether CBM\&As inflows depend on macroeconomic factors. The $\alpha^{\prime} s$ represent the weight on the macroeconomic variables and $\varepsilon_{t}$ is an error term. The response of CBM\&As to lagged CBM\&As, GFTSEAL, GRGDP, ROI, GRXR and INF, as well as the constant term are allowed to differ between a lower and an upper regimes. $R_{L t}(\mathrm{~L}$ standing for lower) is the lower regime that represents the behaviour of foreign investors when $q_{t-d}\left(q_{t}=\frac{1}{n} \sum_{t=1}^{n} G F T S E A L L_{t-i}\right.$ is defined as the average returns over the last $n$ quarters $)$ will be less than some threshold value of $g$ percentage points, where $d$ is the delay lag. $R_{U t}$ (U standing for upper) is the upper regime that describes the behaviour of investors in the upper regime where $q_{t-d}$ lies above $g$ percentage points. Therefore in model (1), the response to macroeconomic factors is allowed to differ between stock market regimes, thereby allowing different behaviours for stock market booms and recessions (when the variable $q_{t-d}$ will be less than $g$ percentage points) ${ }^{1}$.

\footnotetext{
${ }^{1}$ It is worth noting that Franses and Djik (2000) use a similar variable as transition variable in a SETAR model. While LeBaron (1992) considers a measure of volatility as candidate threshold variable.
} 
The nonlinear function $\lambda_{t}\left(q_{t-d} ; \gamma, g\right)$ can take a number of specifications. It could take a threshold specification where CBM\&As inflows would behave linearly but with different speeds of response depending on the value of a given variable (LeBaron, 1992; Franses and van Dijk, 2000). The nonlinear function can be smooth rather than discrete and it could measure, for instance, the weight, at the beginning of period t, that is, $q_{t-d}$ will be less than $g$ percentage points, in which case it is modelled using the logistic function (see Granger and Terasvirta, 1993; and van Dijk et al., 2002).

For this study, we used the logistic function (in which case the model is known as the Logistic Smooth Transition Autoregressive (LSTAR) process) as it allows for a smooth nonlinear adjustment of CBM\&As inflows across regimes. This form of the nonlinear function allows the response of CBM\&As inflows to differ between the two average return regimes, lower and upper. The weight $\lambda_{t}$ is modelled as follows:

$$
\lambda_{t}=1-\frac{1}{1+e^{-\gamma\left(q_{t-d}-g\right) / \sigma_{q_{t}}}}
$$

Equation (2) equates the regime weight $\lambda_{t}$ to the probability that average returns, $q_{t-d}$ will lie below some percentage points, $g$, a constant threshold value. The smoothness parameter $\gamma>0$ is the transition speed of the function $\lambda_{t}\left(q_{t-d} ; \gamma, g\right)$ towards 0 (or 1) as the deviation of the transition variable, $q_{t-d}$ from the constant threshold, $g$, grows larger (or smaller). This transition function has the properties that (i) $\lambda$ becomes constant as $\gamma \rightarrow 0$ and (ii) as $\gamma \rightarrow \infty, \lambda=0$ if $q_{t-d}>$ $\mathrm{g}$ or $\lambda=1$ if $q_{t-d}<\mathrm{g}$ (see Jansen and Teräsvirta, 1996). In general, the weight on $R_{L}$ is greater the larger is the probability that average returns will lie below $g$. If one regime is always 
dominant, our model simplifies to a linear specification. We follow Granger and Teräsvirta (1993) and Teräsvirta (1994) in making $\gamma$ dimension-free by dividing it by the standard deviation of $q_{t-d}, \sigma_{q_{t}}$.

Another popular choice of transition functions is:

$\lambda_{t}=1-e^{-\gamma\left(q_{t-d}-g\right)^{2} / \sigma^{2} q_{t}}$

giving rise to the exponential smooth transition autoregressive (ESTAR) process. However unlike the LSTAR specification which allows for different response to positive and negative deviations of $q_{t-d}$ from the constant threshold value $g$, which is convenient for modelling CBM\&As in the presence of asymmetric behaviour. This is not the case for the ESTAR specification, in which positive and negative deviations from the threshold have the same effect. This model is therefore only able to capture non-linear symmetric adjustment.

\section{Model Hypotheses}

Drawing from the literature discussed above, we set out the model hypotheses that will allow us to address the questions raised on CBM\&As inflows in the introduction. The way in which CBM\&As inflow has changed over the years can be investigated by considering differences in the estimated parameters between regimes. First, we hypothesise that across both regimes $\alpha_{j f}>0$ (an increase in growth in FTSE would attract more CBM\&As inflows); $\alpha_{j y}>/<0$ (an increase real GDP growth would increase or decrease inflows) $\alpha_{j r}<0$ (an increase interest rate

leads to increase in cost of investment hence a fall in CBM\&As inflows) $\alpha_{j e}>/<0$ (an increase in relative prices would lead to a decrease in the UK's competitiveness and hence a fall in merger inflows due to huge capital needed for such investments but an improvement in the terms of trade can foster exports and increase inflows for a small price-taking open economy) $\alpha_{j \pi}>/<0$ (higher 
inflation would deter CBM\&As, but also higher inflation would boost nominal returns and provide a money illusion story often encountered in the literature).

Second, we would expect differences across the two regimes so that under the upper regime, the response to GFTSE to be higher, $\left(\alpha_{U f}>\alpha_{L f}\right)$ and similarly for the response to growth in real GDP $\left(\alpha_{U y}>\alpha_{L y}\right)$ and that the response to interest rate to be smaller in absolute term in the upper regime, $\left(\left|\alpha_{u_{r}}\right|<\left|\alpha_{L_{r}}\right|\right)$, implying that once the return on investment is higher, the cost of investment would act less as a deterrent to the CBM\&As decisions. If $\alpha_{j e}>0$, then we would expect the response to be higher in a buoyant market and therefore $\left(\alpha_{U e}>\alpha_{L e}\right)$. Whereas if $\alpha_{j e}<0$, then we would expect inflow to be less affected if we are in the upper regime, that is, $\left(\left|\alpha_{u_{e}}\right|<\left|\alpha_{L_{e}}\right|\right)$. With respect to inflation, we posit that if $\alpha_{j_{\pi}}>0$, then the money illusion story would be reinforced in a buoyant market, that is, $\alpha_{U \pi}>\alpha_{L \pi}$. Whereas if $\alpha_{j_{\pi}}<0$, we would expect inflation to be a higher deterrent in a pessimistic outset.

\section{Econometric Results}

Our analysis is based on quarterly data 1987q1-2008q1 for the $\mathrm{UK}^{2}$ collected from the Economist Intelligence Unit (EIU) country database. This was cross-checked with the official data of the Office of National Statistics, UK

Table 1 summarises the minimum and maximum values of each series, together with their mean, median, standard deviation, skewness and kurtosis.

\section{Insert Table 1}

\footnotetext{
${ }^{2}$ Macro-economic data were obtained from Economist Intelligence Unit (EIU) country database and checked with the Office of National Statistics, UK. UK inwards cross-border mergers and acquisitions deals completed between 1987 - 2008 period was derived from Thomson One Banker database and compared with data provided in Acquisitions Monthly
} 
Figure 1 provides a plot of the number of CBM\&As inflow. The figure shows the persistent wave type behaviour of the series and also the fact that any increase or decrease is quite smooth thereby supporting our proposition that merger waves tends to follow a smooth transition to regimes.

\section{(Insert Figure 1)}

\section{Linearity and Unit root testing:}

We first consider the Escribano and Jordà (EJ hereafter) (2001) linearity LM test. The null hypothesis in this test $\left(H_{0}\right)$ is that $C B M A I N_{t}$ follows a stationary linear process. The computation of the test is carried out using the F version which is an asymptotic Wald test. If linearity is rejected, we follow the EJ procedure to discriminate between the ESTAR and LSTAR nonlinear models. According to the results, linearity is rejected when the transition variable is $q_{t}$ as suggested by the $\mathrm{p}$-value of the $\mathrm{LM}_{4}$ test. Table 2 shows that for $q_{t}$, the LSTAR representation of the data is preferred to the ESTAR since $H_{0 E}$ presents a lower p-value compared to $H_{0 L}$. Augmented Dickey-Fuller (ADF) and Phillips-Perron (PP) unit root tests as well as the Kwiatkowski et al. (KPSS) stationarity test for all the variables under study are reported in Table 3 Panel A. We note that the null of a unit root cannot be rejected on the basis of the ADF test statistics for all the variables except for $G R X R_{t}$, the annual growth rate in the real effective exchange rate index. While the PP test suggests that only inflation and the interest rate are nonstationary series. The KPSS test rejects the null of stationarity for the interest rate and the 
inflation rate $^{3}$. It should also be noted that the test also rejects the null of stationarity at the $10 \%$ level for CBMAIN $_{t}$.

\section{(Insert Table 3 here)}

On this basis, the only variable for which the order of integration is unambiguously one according to all the three tests is the interest rate and we therefore use the change in the interest rate in our study. We pursued further analysis to determine the time series properties of our main variable of interest ${ }^{4}, C B M A I N_{t}$. Within the nonlinear framework the literature provides some evidence that unit root tests have low power if the true data generating process is an ESTAR (see Taylor, Peel, and Sarno, 2001), and the unit roots results above for CBMAIN $N_{t}$ has to be interpreted with that caveat in mind.

Recent research has developed new testing procedures of the null of a unit root process against an alternative of a nonlinear ESTAR process ${ }^{4}$ which is globally mean reverting. Kapetanios, Shin, and Snell, 2003 (KSS hereafter) derived a unit root tests of nonlinear (and asymptotically stationary) alternative that has better power than the standard Dickey-Fuller test in the region of the null ${ }^{5}$. Under the null hypothesis $\left(H_{0}: \gamma=0\right)$ and of unit root $\left(\alpha_{1}=1\right)$, using a first-order Taylor approximation to the transition function around point $\gamma=0$, they obtain the following

\footnotetext{
${ }^{3}$ Nobay et al. (2008) showed that the inflation rate is a globally mean reverting process within an ESTAR framework ${ }^{4}$ The smooth transition model has the form $y_{t}=\sum_{i=1}^{p} \alpha_{i} y_{t-1}+\left(1-F_{t}\right)\left\{\sum_{t=1}^{r} \delta_{i} y_{t-1}\right\}+u_{t}$, where $\alpha_{i}$ and $\delta_{t}$ are constants, $u_{t}$ is assumed to be Gaussian and $F_{t}$ is the continuous transition function, bounded between zero and unity. In the ESTAR model, $F_{t}=e^{-\gamma\left(y_{t-d}-c\right)^{2}}$ and under the LSTAR model, the logistic form is $F_{t}=\frac{1}{1+e^{-\gamma\left(y_{t-d}-c\right)^{2}}}$

${ }^{5} \mathrm{KSSa}$ examined the properties of their tests under three different assumptions of stochastic processes: (i) with no constant, no trend; (ii) with nonzero constant; (iii) with linear deterministic trends. In the cases where $y_{t}$ exhibits significant constant or trend, $y_{t}$ should be viewed as the de-meaned and/or de-trended variable.
} 
auxiliary regression where lags of the dependent variable might be included in the case of error autocorrelation,

$$
\Delta y_{t}=\sum_{j=1}^{p} \theta_{j} \Delta y_{t-j}+\delta y_{t-1}^{3}+u_{t}
$$

Testing for $\delta=0$ against $\delta<0$ corresponds to testing the null hypothesis of a unit root, and the $\mathrm{t}$ statistic is given by

$$
t_{N L}=\frac{\hat{\delta}}{s . e(\hat{\delta})}
$$

where s.e $\hat{\delta}$ denotes the estimator standard error. The asymptotic distribution of equation (7) is not standard since under the null, the underlying process is non-stationary ${ }^{6}$.

Kiliç (2003) developed an alternative testing method to detect the presence of nonstationarity against nonlinear but globally stationary STAR process that differs from KSS in the way it deals with the nuisance parameter that occurs under the null. It is argued that, the advantages of Kiliç procedure over KSS are twofold. First, it computes the test statistic even when the threshold parameter needs to be estimated in addition to the transition parameter. Second, it has a higher power. Kiliç test applies to the following expression,

$$
\Delta y_{t}=\phi y_{t-1}^{3}\left(1-e^{-\gamma\left(m_{t}-c\right)^{2}}\right)+u_{t}
$$

where $m_{t}$ is the transition variable, in this case $m_{t}=\Delta y_{t}$. The null hypothesis of $H_{0} ; \phi=0$ (unit root case) is tested against the alternative $H_{0} ; \phi<0^{7}$.

\footnotetext{
${ }^{6}$ The test statistic (equation 7) converges weakly to a functional of Brownian motions (see KSS).

${ }^{7}$ To overcome identification problems (of $\gamma$ and $c$ ) under the null hypothesis, Kiliç (2003) uses the largest possible $t$ value for $\phi$ over a space of values for $\gamma$ and $c$, in particular (sup- $t$ ). We have decided to use an interval for $\gamma$ according to values usually found in our simulation results for each degree of aggregation. The values of $c$ have been selected as corresponding to the ordered values of $m_{t}$ and discard $10 \%$ of the highest and smallest values
} 
We applied both KSS and Kiliç tests to CBMAIN and the results are shown in Table 3 Panel B.

In both cases the null hypothesis that CBMAIN is a random walk process could be rejected at the $5 \%$ level in favor of a STAR alternative ${ }^{8}$.

\section{LSTAR estimation}

We estimate a slightly different version of the LSTAR model equation (1) as it works better for our purposes. The new specification is given by:

$$
\begin{aligned}
& \text { CBMAIN }_{t}=\alpha_{U 0}+\alpha_{U i}(L) \text { CBMAIN }_{t}+\alpha_{U f} \text { GFTSEALL }_{t}+\alpha_{U y} \text { GRGDP }_{t}+\alpha_{U r} \text { ROI }_{t}+ \\
& \alpha_{U e} R R_{t}+\alpha_{U \pi} I N F_{t}+\lambda_{t}\left(q_{t-d} ; \gamma, g\right)\left(\alpha_{L 0}+\alpha_{L i}(L) \text { CBMAIN }_{t}+\alpha_{L f} \text { GFTSEALL }_{t}+\right. \\
& \left.\alpha_{L y} \text { GRGDP }_{t}+\alpha_{L r} \text { ROI }_{t}+\alpha_{L e} R X R_{t}+\alpha_{L \pi} I N F_{t}\right)+\varepsilon_{t}
\end{aligned}
$$

where the weight $\lambda_{t}$ is modelled as follows:

$$
\lambda_{t}=\frac{1}{1+e^{\gamma\left(q_{t-d}-g\right) / \sigma_{q_{t}}}}
$$

However note the slight modification with the interpretation of the model. As $q_{t-d} \rightarrow \infty$, $\lambda_{t}\left(q_{t-d} ; \gamma, g\right) \rightarrow 0$ and as $q_{t-d} \rightarrow-\infty, \lambda_{t}\left(q_{t-d} ; \gamma, g\right) \rightarrow 1$. Therefore the $\alpha_{U}{ }^{\prime} s$ are the relevant parameters when we are in the upper regime. However when $\lambda_{t}\left(q_{t-d} ; \gamma, g\right)=1$, the relevant parameters are a summation over $\alpha_{U}$ and $\alpha_{L}$.

The results from estimating model equation (9), are presented in Table $4^{9}$.

\footnotetext{
${ }^{8}$ These values are significant using the conventional critical values provided in KSS and Kilic (2003)).

9 In estimation we have made use of lag (first lag), actual and forward looking versions of the explanatory variables. For the forward looking specification, we have made use of perfect foresight by replacing the explanatory variables with actual one-period ahead outcomes. In the paper, we report the specification which provides the best model fit, that is, actual values.
} 
Given the time length of the sample and the use of a heavily parameterized nonlinear model, we removed the insignificant variables in order to obtain a well determined simplified model. ${ }^{10}$

Table 4, column (i) reports nonlinear least squares estimate for the lower regime and column (ii) presents corresponding nonlinear estimates for the upper regime ${ }^{11}$. The diagnostic tests appear to indicate no serious misspecification in the model. The nonlinear model indicates that macro economic factors examined in the study explain well over 60 percent of variation in inward crossborder mergers \& acquisitions. We also note from our results not provided here that our nonlinear model dominates a linear version of the model. It has a lower standard error and better explanatory power of about $15 \%$ and therefore provides a better explanation of the inflow of CBM\&As on the basis of the R-bar squared. We estimate $g=7.96 \%$ and the results in Table 4 suggest that four factors, namely, share prices growth, growth in real GDP, inflation rate and growth in the real exchange rate appear to have a bearing on the inflows of mergers and acquisitions in the UK.

(Insert Table 4 here)

There are a number of key findings that help us to answer the questions that we put forward in the introduction. An important finding emanating from the parameters on the lag polynomial is that there appears to be no persistence in the lower regime however the upper regime shows a high degree of persistence which is consistent with the findings of similar studies using Markov

10 In estimation, we tried $G F T S E A L L_{t-i}$ for $\mathrm{n}=1, \ldots, 4$ and a case of $\frac{1}{n} \sum_{i=1}^{n} G F T S E A L L_{t+i}$ with $\mathrm{n}=1, \ldots, 4$ as possible variables in the transition function. In estimation, we report the case which provides the best fit, based on the lowest p-value obtained in Table 2, namely, $q_{t}=\frac{1}{4} \sum_{i=1}^{4}$ GFTSEALL $_{t-i}$.

${ }^{11}$ Note that when the model is in the lower regime, the response is a summation over the lower and the upper regime. 
Switching models. The results suggests that if growth of FTSE is greater than 7.96 threshold, a 1 percent increase in growth of FTSE yields 0.19 increase in CBM\&As inflows. The finding that a growth in stock prices (FTSE) tends to increase CBM\&A inflows is in line with the conclusion drawn by Nelson (1959) who found a positive correlation between changes in the merger activities and changes in the stock prices. Other studies such as Melicher, Ledolter and D’Antonio (1983) and Benzing (1991) have also argued that higher stock prices indicate the prospects of future economic growth, increased in profitability and hence higher level of CBM\&As inflows. The studies by Shleifer and Vishny (2003) and Rhodes-Kropf and Viswanathan (2004) have also rendered support for this finding. The results also indicate an asymmetric response to the growth in real exchange rate. Under the lower regime, a 1 percent increase in the growth of the real exchange rate results in a fall of CBM\&As inflows by 0.76 and an increase by 0.83 under lower and upper regimes respectively. This is surprising in that it was expected that growth in the real exchange rate would lead to a fall in inward CBM\&As activity but this appears not to be the case. Perhaps, this finding may be explained by the fact that in open economy such as the UK, an increase in relative prices leads to an improvement in the terms of trade and therefore fostering exports and consequently an increase in the inflow of CBM\&As. However, it is important to note that a growth in GDP and inflation lead to a fall in inwards cross-border mergers and acquisitions by 5.12 and 4.94 respectively. The finding that growth in GDP leads to a fall in inward acquisitions lends some support to the notion that a higher GDP leads to a higher level of cash reserve in the hands of local firms and these firms may use the excess funds to acquire local firms to increase the size of their companies and gain market power. Given the existence of market imperfections in the global market for product and service such as transaction costs, costs associated with barriers to entry and liability of "foreignness", local firms 
are more likely to have an advantage over foreign acquirers. However, it is important to point out that this result is at variance with the conclusion drawn by Anand and Kogut (1997) and Globerman and Shapiro (1999) who suggest that higher GDP in the host country would lead to more inward M\&As. Regarding the negative impact of inflation, the results also appear unsurprising in that higher inflation have the effect of eroding the purchasing power within an economy and therefore may serve as a deterrent to inward acquisitions.

\section{Conclusion}

The study has analysed a quarterly data set of macro economic influences on inward cross-border mergers and acquisitions activity into the UK over the period of 1987 - 2008. It is pertinent to point out this study represents the first attempt to analyse the relationship between macro economic influences on cross border mergers and acquisitions using a nonlinear time series model -Smooth Transition Auto-Regressive (STAR) which is 'smooth' by nature. This study, therefore, reports a new and significant contribution in an under-research area by lending support to our proposition that merger waves and patterns tend to follow a smooth transition. Our analysis suggests that nonlinear model appears to be a better approach to capture and reveal the structure in data which are missed by linear models used so far to examine the wave behaviours of merger and acquisitions.

The study also find that macroeconomic factors, namely, share prices, growth in real GDP, inflation rate and growth in the real exchange rate play an important role in the trends and patterns of cross borders mergers and acquisitions inflows into the UK. The results imply that macro-economic factors drive firm level decisions to invest abroad. The results also indicate that CBM\&As inflow is more persistent during stock market booms and also there are asymmetric 
response to inflows with regards to the real exchange rate. Another finding which appears quite surprising is that the growth in the real exchange rate leads to a rise in inward CBM\&As activity contrary to the findings of Harris and Ravenscraft (1991), Kang (1993), Dewenter (1995) and Goergen and Renneboog (2004) whose studies reported that a fall in relative prices tends to a rise in inwards investments.

The insignificant impact of real interest rates on inward CBM\&As appears surprising in that, it is argued that high interest would deter investment inflows but this appears not to be the case. Perhaps the interest patterns in the UK over the past 20 years may help provide an explanation to this finding. In the late 1980s to the middle of 1990s, the UK witnessed steady rise in interest rate compared to 1997 to 2008 when interest rate fell to its lowest level in five decades. The combined effects of interest rates of the rise and fall may help explain the results. Despite the significant contribution of this paper, further studies appear warranted. Future studies should to explore these issues using a Smooth Transition Auto-Regressive model but for relatively longer period of time.

\section{References:}

Ali-Yrkko, J. (2002) Mergers and acquisitions: Reasons and Results, Discussion paper series, No. 792, The Research Institute of the Finnish Economy (ETLA).

Anand, J. and Kogut, B. (1997) Technological capabilities of countries, firm rivalry and foreign direct investments, Journal of International Business Studies, Vol. 28(3), pp. 445-467.

Aw, M. and Chatterjee, R. (2004) "The performance of UK firms acquiring large cross-border and domestic takeover targets", Applied Financial Economics, Vol. 14, pp. 337-349.

Becketti, S. (1986). Corporate mergers and the business cycle, Federal Reserve Bank of Kansas City Economic Review, 71, pp.13-26

Benzing, C. (1991) "The Determinants of Aggregate Merger Activity before and after CellerKefauver", Review of Industrial Organization, Vol. 6, pp. 61-72. 
Bradley, M. Desai, A. and Kim, E.H. (1988). Synergistic gains from corporate acquisitions and their divisions between the stockholders of target and acquiring firms, Journal of Financial Economics, 21, 1 (May), 3-40.

Carow, Kenneth, Heron, Randall and Saxton, Todd (2004). Do Early Birds get the Reurns? An Empirical Investigation of Early-Mover Advantage in Acquisitions, Strategic Management Journal, 25 (6), pp. 563-585

Conn, R.L. and Connell, F. (1990) International mergers: Returns to US and British firms, Journal of Business Finance \& Accounting, Vol. 17(5), pp. 689-711.

Crook, J. (1995) Time series explanations of merger activity: some econometric results, International Journal of Applied Economics, Vol. 9, pp. 58-85.

Cushman, D.O. (1985). Real Exhange rate risk: Expectations and the level of direct investments, Review of Economics and Statistics, 67 (May), pp. 297-308.

Dewenter, K.L. (1995) Do Exchange Rate Changes Drive Foreign Direct Investment? Journal of Business, Vol. 68(3), pp. 405-433..

Diebold and Lindner (1996) Fractional integration and internal prediction, Economic Letters, Vol. 50, pp. 305-313.

Evenett, S.J. (2003) "The Cross-border Mergerand Acquisitions Wave of Late 1990s", Cambridge, MA, NBER Working Paper No. 9655.

Franses, P. H. and van Dijk, D (2000). Nonlinear Time Series Models in Empirical Finance, Cambridge, Cambridge University Press.

Froot, K.A. and Stein, J.C. (1991) Exchange rates and foreign direct investment an imperfect capital markets approach, Quarterly Journal of Economics, Vol. 10 (4), pp. 1191-1217.

Gonzalez, P. Vasconcellos, G.M. and Kish, R.J. (1998) “Cross-border Mergers and Acquisitions: The Undervaluation Hypothesis", The Quarterly Review of Economics and Finance, Vol. 38, No. 1, pp. 25-45.

Goergen, M. and Renneboog, L. (2004) "Shareholder wealth effects of European Domestic and Cross-border Takeover Bids”, European Financial Management, Vol. 10, No.1, pp. 9-45.

Geroski, P.A. (1984) "On the relationship between aggregate merger activity and the stock market”, European Economic Review, Vol. 25, pp. 223-233.

Globerman, S. and Shapiro, D.M. (1999) The impact of government policies on foreign direct investment: the Canadian experience, Journal of International Business Studies, Vol. 30(3), pp. 513-532. 
Golbe, D. and White, L. (1988) Catch a wave: The time series behavior of mergers, Review of Economics and Statistics, pp. 493-499.

Granger, C.W.J. and T. Teräsvirta (1993). Modelling nonlinear economic relationships, Oxford University Press, Oxford.

Gregory, A. and McCorriston, S. (2005). Foreign acquisitions by UK limited companies: Shortand long-run performance, Journal of Empirical Finance, Vol. 12(1), pp. 99-125.

Hamilton, J.D. (1990). Analysis of Time Series Subject to Changes in Regime, Journal of Econometrics, Vol. 45, pp.39- 70 .

Haque, M. Harnhirun, S. and Shapiro, D. (1995) "A Time Series Analysis of Causality Between Aggregate Merger and Stock Prices: The Case of Canada”, Applied Economics, Vol. 27, pp. 563568

Harris, R. and Ravenscraft, D. (1991) The role of acquisitions in foreign direct investment: evidence from the US stock market, Journal of Finance, Vol. 46, pp. 825-44.

Healy, P.M. and Palepu, K.G. (1993) "International Corporate Equity Acquisitions: Who, Where and Why?", Foreign Direct Investment, Kenneth A. Froot (ed.), The University of Chicago Press, Chicago and London.

Hymer, S.H. (1976). The International Operation of National Firms: A Study of Direct Foreign Investment, Cambridge MA: MIT Press.

Hodgkinson, Lynn and Partington, Graham, H. (2007). The Motivation for Takeovers in the UK, Journal of Business Finance \& Accounting, 35 (1)\&(2), pp.102 -126.

Jansen, E.S.and Terasvirta, T., 1996. Testing Parameter Constancy and Super Exogeneity in Econometric Equations, Oxford Bulletin of Economics and Statistics, Vol. 58(4), pages 735-63.

Kang, J. K. (1993). The international market for corporate control: Mergers and acquisitions of US firms by Japanese firms, Journal of Financial Economics, Vol. 34, pp. 345-371.

Kapetanios, G., Yongcheol, Shin. and Andy Snell (2003). Testing for a Unit Root in the Nonlinear STAR Framework. Journal of Econometrics, Vol 112, pp. 359-379.

Kilic, R. (2003). A Testing Procedure for a Unit Root in the STAR Model. Working Paper, School of Economics, Georgia Institute of Technology.

Kindleberger, Charles (1969). American Business Abroad: Six Lectures on Direct Investment (New Heaven, Yale University Press. 
Kish, R.J. and Vasconcellos, G.M. (1993) An empirical analysis of factors affecting cross-border acquisitions: US-Japan, Management International Review, Vol. 33 (3), pp. 227-245.

LeBaron, B., (1992). Some relationships between volatility and serial correlations in stock market returns, Journal of Business, Vol 65, pp. 199-219.

Markides, C. and Ittner, C.D. (1994) Shareholders benefit from corporate international diversification: Evidence from US international acquisitions, Journal of International Business Studies, Vol. 25(2), pp. 343-366.

Mathur, I., Rangan, N., Chhachhi, I. and Sundaram, S. (1994) International acquisitions in the United States: Evidence from returns to foreign bidders, Managerial and Decision Economics, Vol. 15(2), pp. 107-118.

Melicher, R. Ledolter, R.W.J. and D'Antonio, L. (1983) A Time Series Analysis of Aggregate Merger Activity, Review of Economics and Statistics, Vol. 65, pp. 423-430.

McCann, M. (2001) "Cross-border Acquisitions: The UK Experience”, Applied Economics, Vol. 33, pp. 457-461.

Nakamura, R.H. (2004) “To Merger and Acquire When the Times are Good? The Influence of Macro factors on the Japanese M\&A pattern", Working Paper No. 197, The European Institute of Japanese Studies, Stockholm School of Economics, Sweden.

Nelson, R.L. (1959) Merger Movements in American Industry, 1895-1956, Princeton: Princeton University Press.

Rhodes-Kropf, M., Robinson, D. and Viswanathan, S. (2005) Valuation Waves and Merger Activity: The Empirical Evidence, Journal of Financial Economics, Vol. 77, pp. 561-603.

Resende, M. (2005) "Mergers and Acquisitions Waves in the UK: A Markov-Switching Approach", EUI Working Paper Eco. No. 2005/4, Department of Economics, European University Institute.

Sharma, Divesh, S. and Ho Jonathan 2002. The Impact of Acquisitions on Operating Performance: Some Australian Evidence, Journal of Business Finance \& Accounting, 29, January / February, 155 - 200.

Shleifer, A. and Vishny, R. (2003) Stock Market Driven Acquisitions, Journal of Financial Economics, Vol. 70, pp. 295-311.

Shughart, W.F. and Tollinson, R. D. (1984). The Random Character of Mergers', RAND Journal of Economics, Vol. 15, pp. 500-509.

Steiner, Peter, O. 1975. Mergers: Motives, Effects, and Policies, University of Michigan Press, Ann, Arbor. 
Taylor, M.P., Peel, D.A., and Sarno, L., (2001). Nonlinear Mean-Reversion in Real Exchange Rates: Toward a Solution to the Purchasing Power Parity Puzzles. International Economic Review, Vol 42, pp. 1015-1042.

Town, R.J. (1992). Mergers Waves and the Structure of Merger and Acquisition Time-Series', Journal of Applied Econometrics, Vol. 7, pp. 83-100.

UNCTAD (2000) "World Investment Report 2000: Cross-border Mergers and Acquisitions and Development", New York and Geneva: United Nations.

UNCTAD (2006).

van Dijk, D., Teräsvirta, T., and Franses, P.H., (2002). Smooth transition autoregressive models - a survey of recent developments, Econometric Reviews, Vol 21, pp. 1-47.

Vasconcellos, G.M., Madura, J. and Kish, R.K. (1990) An empirical investigation of factors affecting cross-border acquisitions: The US/UK experience, Global Finance Journal, Vol. 1(3), Summer, pp. 173-189.

Vasconcellos,G.M. and Kish, R.J. (1998) Cross-border mergers and acquisitions: the EuropeanUS experience, Journal of Multinational Financial Management, Vol. 8(4), pp. 431-450.

Vernon, R. (1966). International Investment and International Trade in the product cycle, Quarterly Journal of Economics, LXXX, (May), 190-207.

Weston, J. (1953). The Role of Mergers in the growth of large firms, Berkeley, CA, University of California Press.

Yagil, J. (1996) "Mergers and Macroeconomic Factors", Review of Financial Economics, Vol. 5(2), pp. 181-190.

Yantek, Thom and Gartrell, Kenneth, D. (1988). The Political Climate and Corporate Mergers: When Politics Affects Economics, The Western Political Quarterly, Vol. 41, No. 2, pp. 309-322. 
Figure 1: Number of CBM\&As inflow (quarterly 1987q1-2008q1)

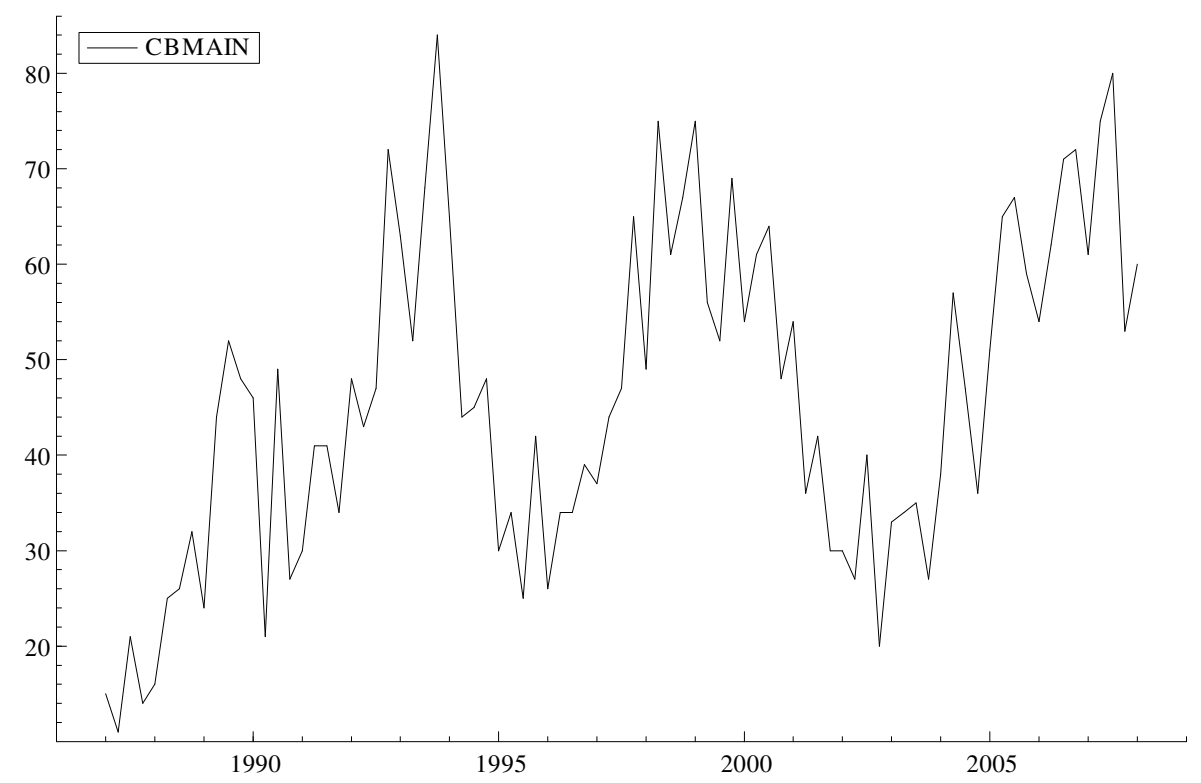

Table 1: Summary Statistics of the observed variables

\begin{tabular}{lllllll}
\hline & CBMAIN & GFTSEALL & GRGDP & ROI & GRXR & INF \\
\hline Minimum & 11 & -33.42 & -3.40 & 3.50 & -15.50 & 0.54 \\
Maximum & 84 & 28.12 & 5.75 & 15 & 16.96 & 7.96 \\
Mean & 45.88 & 6.34 & 3.03 & 7.15 & 0.32 & 2.63 \\
Median & 46 & 10.37 & 3.64 & 6 & -0.57 & 1.92 \\
Std Dev & 17.14 & 13.94 & 1.85 & 3.19 & 0.29 & 1.86 \\
Skewness & 0.10 & -0.95 & -1.72 & 1.19 & 0.05 & 1.54 \\
\hline Kurtosis & 2.24 & 3.32 & 5.90 & 3.28 & 3.56 & 4.25 \\
\hline
\end{tabular}


Table 2: LM-type Test for Nonlinearity and STAR Model Selection

\begin{tabular}{llll}
\hline & $\mathrm{LM}_{4}$ & $H_{0 L}$ & $H_{0 E}$ \\
\hline $\begin{array}{l}\text { Transition } \\
\text { variable }\end{array}$ & & & \\
Trend & 0.960 & 0.746 & 0.724 \\
$q_{t}$ & 0.054 & 0.132 & 0.010 \\
$q_{t-1}$ & 0.444 & 0.444 & 0.322 \\
$q_{t-2}$ & 0.453 & 0.833 & 0.291 \\
$q_{t-3}$ & 0.806 & 0.861 & 0.292 \\
\hline$q_{t-4}$ & 0.823 & 0.985 & 0.379
\end{tabular}

Note: p-values of $\mathrm{F}$ variants of the LM-type tests used in the specification procedure of Escribano and Jordà (2001).

The auxilliary tests are applied in a linear version of equation (1) with 4 lags of $C B M A I N_{t}$ and the macroeconomic variables under study.

Table 3: Unit Root Tests

\begin{tabular}{llll}
\hline Panel A & Augmented DF & PP & KPSS \\
\hline CBMAINt & -2.34 & $-3.52^{* * *}$ & $0.37 *$ \\
GFTSEALLt & -1.94 & $-3.55^{* * *}$ & 0.13 \\
GRGDPt & -2.34 & $-2.75^{*}$ & 0.34 \\
ROIt & -1.10 & -1.48 & $0.80^{* * *}$ \\
$\Delta$ ROIt & $-2.62^{*}$ & $-3.19 * *$ & 0.09 \\
GRXRt & $-2.87 *$ & $-2.70^{*}$ & 0.07 \\
INFt & -1.47 & -1.65 & $0.67 * *$ \\
& & & \\
Panel B & KSS & Kilic & \\
\hline CBMAINt & $-3.59 * *$ & $-2.53 * *$ \\
\hline Note: $*(* *)(* *)$ denotes significance at $10,5,1 \%$ level respectively
\end{tabular}


Table 4: Parameter Estimates for Equation (1)

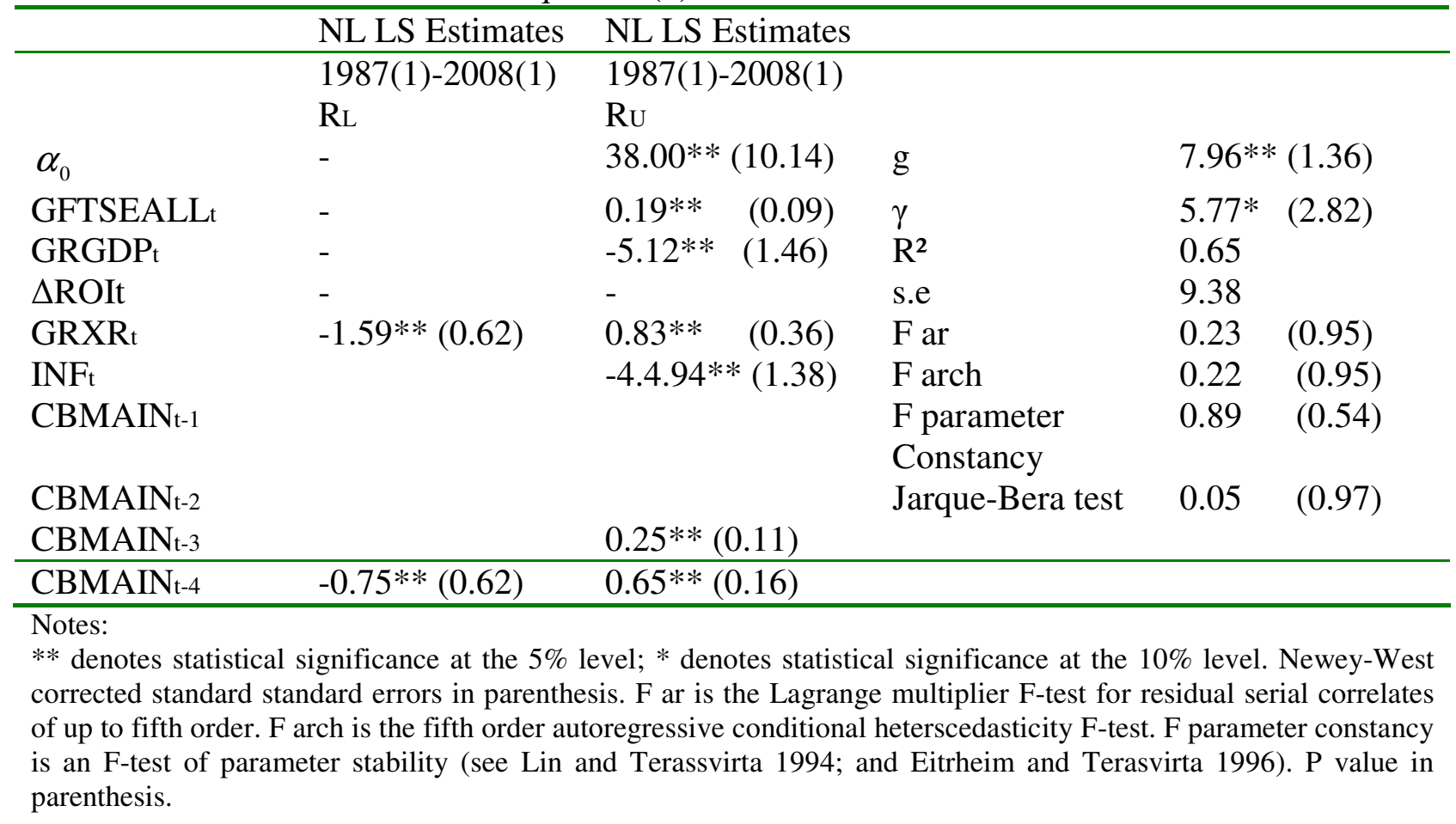

